\title{
Educational Internet Resources in Turkic Languages
}

\author{
Aliya A. Kabirova ${ }^{1}$, Kadriya S. Fatkhullova ${ }^{2}$,Elvira N. Denmukhametova ${ }^{3}$, Kuandik S.Kulmanov ${ }^{4}$ \\ 1, 2,3, Kazan Federal University, Leo Tolstoy Institute of Philology and Intercultural Communication \\ ${ }^{4}$ L.N. Gumilev Eurasian National University (Kazakhstan, Astana) \\ Email: aakabirova@gmail.com
}

Received: 21st October 2017 Accepted: 16th November 2017, Published: 31st December 2017

\begin{abstract}
Internet technology has become an integral part of a modern person's life. Obtaining the necessary information from online resources and using them for communication expand the horizons of man, provide various opportunities for learning languages. However, there is the impact of the Internet on the functioning and development of the literary language. This article provides an overview of educational Internet resources, allowing distant learning of the Turkic languages, and findштп the necessary information on the various academic disciplines. Using the example of the Tatar language the article shows the most popular among users educational Internet resources that contain additional information on the various school subjects taught in the national (Tatar) language, as well as sources for selfeducation.

The purpose of this study was to examine linguistic features of the material of such educational portals like belem.ru, http://giylem.tatar, http://elbette.ru that are Tatar sources in the Runet. In the study the initial analysis and presentation of the material was made by using descriptive method, thematic analysis of the texts was given, and also the availability and style of presentation of materials were evaluated. These portals help teachers in Tatar schools and grammar schools to find modern scientific and popular materials, interactive programs in Tatar language and literature, geography, physics, biology, chemistry, mathematics, and other disciplines. Comparative analysis allowed to make a rating of useful and interesting materials for both teachers and students. Through the prism of the interpretative analysis specificity of the different variants of the transformations used for the translation of materials into the Tatar language from other languages was determined. Using the method of continuous sampling, the factual material was selected, there were cases of incorrect transformation, which complicated the perception of information by portal users.

Educational portals in the Tatar language are a modern comprehensive information environment, therefore their use and their study is the most important necessity for all participants of educational process whose aim is to improve professional skills. They serve the development and propagation of the Tatar language as one of the representatives of the
\end{abstract}

Turkic languages that are of interest to a wide range of Internet users.

The results of the study will be useful for both those who are teaching and learning languages and are interested in materials in national languages. It should be said that modern information technology has become an integral part of the educational process in the study of Turkic languages.

Keywords: Internet Resources, The Turkic Languages, Tatar Language, Learning, SelfEducation.

\section{Introduction}

The rapid development of science, the rapid updating of information in modern life require an update of conditions in the educational environment. Availability of information base through Internet resources considerably enriches and facilitates the work of both teachers and learners. Time brings about changes in everything, including the traditional ways of teaching languages and other subjects in secondary schools, in the system of secondary special and higher education. It is well known that the introduction of new information and communication technologies increases the access to study many languages, including rare ones, forms a system of open education, changes the understanding of the opportunities available to the person wishing to study the language as a second or foreign. The phenomenon of innovation encompasses not only the creation and diffusion of innovations, but also describes the changes in mindset, life style activities, that these innovations are connected with. Innovation process in language learning is associated with the transition of education to a qualitatively different state, with a revision of outdated rules and regulations, roles of the teacher and students, and often with their revision $[1$, $2,3,10,11]$.

A Turkic language is spoken by approximately 170 million people who live in different countries, and represent around 30 nationalities. Thanks to the Internet modern people can learn these languages with the help of the Runet. For example, on the official website www.kazakhtest.kz you can test your level of proficiency in Kazakh in online mode, but to study it the Internet portal Soyle.kz [4], which provides free services for official language learning will help. On a special website www.onatili.uz, where the theoretical and practical courses, online 
library, and scholarly articles on Uzbek linguistics are placed you can learn the Uzbek language [5]. There are several sites for independent and remote study of the Bashkir language. For example, by using site http://f13.ucoz.net you can learn the language at the primary level [6]. A model of the efficient and most convenient service for distance learning is the model of online schools teaching the Tatar language "ANA TELE", which was created in partnership with EF Education First in 2013 . It is a unique opportunity for intensive active mastery of the Tatar language as means of interpersonal and intercultural communication. Advantages of remote schools compared to the traditional form lies in the fact that learning is communication-oriented and is conducted at the levels in accordance with the international language competence; the study material is presented visually; an internal feedback as a mechanism of selfcontrol is provided. Computer technology provides the user with the possibility of individualization and the intensification of high learning [7,8]. The educational process aimed at the development of communicative competence of users, which is understood as the ability to perceive, understand, and generate the statement in the target language within a particular situation [9]. Modern conditions of globalization often lead to the disappearance of the culture on paper. On the one hand, Internet technologies allow you to quickly find information, on the other hand, there is a threat of development of the material from the untrusted source. The creation of educational resources: websites, web pages by the professionals in different scientific areas is a way out of this situation. Uploading the highly-demanded materials in Turkic languages is especially important for us.

The scientific novelty of this study lies in the fact that the paper first attempts to study the educational Internet resources in Tatar language belem.ru, http://giylem.tatar, http://elbette.ru that contain information on different branches of science, including the Tatar world and studies of Tatar language and culture.

We hope that this work is a small contribution to the development of the Tatar linguamethodics, ethnolinguistics, study of the Tatar culturet and it will arise the interest in pedagogical workers, the users of the Tatar Internet resources.

\section{Materials and Methods}

In the process, we used the following research methods: comparative and descriptive methods, the method of continuous sampling, interpretive and contextual analysis. Using the descriptive method was followed by initial analysis and presentation of the material. Using comparative analysis we have compiled a ranking of useful and entertaining materials from each source, both for teaching and for the learner. The method of continuous sampling was used in selection of material for the linguistic analysis of the translated texts. Content and contextual analyses were used to study sources on the structure or substantive content.

Material for the study consists of texts from the following Internet sources: Tatar educational portal UPR: www. belem.ru, the web page of the project Giylem http://giylem.tatar, a scientifically popular online portal with video lectures http://elbette.ru.

\section{Results}

The impact of the Internet on various spheres of public life is of permanent interest in the scientific community and among the General mass audience. If some see the positive side of the Internet technology in the form of broadening people's outlooks, the desire for independent search of information, etc. (especially at school age), others point to the negative side of the material independently obtained from these sources. Therefore, the study should use only those sources, where the available information is checked for accuracy and written in the literary Tatar language. Thanks to them, the student must enrich his knowledge and obtain complete information for use in further communication. To date, these Internet resources in Tatar language are the following: belem.ru, http://giylem.tatar, http://elbette.ru. We believe it is necessary to dwell briefly on each of them.

Tatar educational portal belem.ru has been operating since 2007. Since the establishment it assists teachers, leading professional activities in their native language, as all the information on the site is given in the Tatar language. The portal contains a lot of interesting things in the field of education, legislative information, a directory of resources for different school subjects, video and audio albums. Through the portal you can learn about the regional contests, held in the Tatar language, as well as to obtain information about the events organized by the governmental portal. It serves as a platform for exchanging the best educational experience among schoolteachers, as they post here thematic plans, working programs, lesson plans and extra-curricular activities, as well as discuss issues on preparation for RNE, CSE communicate in the chat. Here are links to media sites in Tatar language. websites of creatively working teachers of secondary schools, the materials of the Ministry of culture and the Ministry of education and science of the Republic of Tatarstan. The portal has a large library resource.

The study showed that all the information placed on this portal, is formed in compliance with the norms of the modern Tatar literary language. This is because the main users of the portal are teachers, and all information is aimed at them. Students are also active users who are attracted primarily to audio, video materials and the library. It is necessary to emphasize that translated texts from other languages (mostly Russian) meet language standards. 
Education portal http://giylem.tatar functions since 2015 on the basis of Institute of Philology and intercultural communication named after Leo Tolstoy, Kazan Federal University. It was created with the help of the initiative of the talented and gifted young people - students of Kazan Federal University. The main objective of the portal is to familiarize the wide circles of the population speaking the Tatar language with popular scientific materials and scientific achievements. On the pages of this portal you can also find information about the great discoveries in biology, chemistry, geography, which are recorded in various encyclopedias and scientific works. It is mostly translated from Russian, English and Turkish languages. Along with scientific and educational materials, the attention is paid to the subject of the history and culture of Tatars, linguistic features and problems of Tatar linguistics. The materials published on this page are aimed at the wide audience, but its active users are students and the more mature population. A peculiarity of this project is an active discussion in the chat, because users respond to the publication, provide comments, and sometimes supplement the material. All this correspondence is conducted in the Tatar language. Linguistic analysis of the published materials showed that the translated texts have some language deficiencies, particularly trace forms that violate the speech pattern of the Tatar language. There is a noticeable difficulty in the translation of certain terms that are ambiguous in the texts. But after each publication in the review updated translations and recommendations to the interpreter appear. In this way, the users themselves make corrections in the texts and correct deficiencies.

Popular scientific online portal with video lectures http://elbette.ru was established in 2016 using the example of similar major Federal projects of the Russian Federation: "Postnauka" - a popular science project, containing lectures on various fields of scientific knowledge, ranging from anthropology to cosmology; "Arzamas" - a project, specializing in the Humanities; "Open University" - a project with lectures about modern culture, etc. The Online portal "Elbette" aims to focus the lectures on Tatar language and literature, history and culture of the Tatar people. Users of this portal are those who are interested, first, in the Tatar world, and secondly, science in the broadest sense of the word. Here are lectures on current topics of Tatar culture and confessions of the Tatars. They are given by prominent public figures, Tatar scientists, archeologists, specialists in culture and art in the user-accessible scientific Tatar language. Among them, the historian Rafael Khakimov, literary Daniya Zagidullina, Alfat Zakirzyanov, historian and archaeologist Damir Iskhakov, linguists Alfiya Yusupova, Zoe Kirillov, musicologist Sagit Khabibullin, musician Elmir Nizamov and others. Despite the short period of use, the portal has already gained great popularity among
Internet users. It may be of interest for not only teachers of schools but can be useful for a wide range of users. The language of the lectures is clear, not filled with terminology of a narrow profile that makes the material popular. A lecture lasts 15-20 minutes, which helps listeners to perceive the information. It is interesting, that the lecturers in explaining the material on a particular subject express their point of view on this issue and leave users open-ended questions for reflection.

\section{Discussion}

1. Educational portals in the Tatar language meet the realities of today and provide each user with the information in an accessible form. They contain additional information on the various academic disciplines taught in the Tatar language, as well as a source for self-education for students. Internet resources are a comprehensive modern information environment, therefore their use and their study is the most important necessity for all participants of the educational process.

2. Educational portals provide users a unique opportunity to study Turkic languages, to improve communicative skills and deepen linguistic knowledge, to build their speech, language and sociocultural competencies. The benefits of distance courses in comparison with traditional methods is that they teach in levels, in accordance with the international language competence; the study material is presented clearly; internal feedback as a mechanism of self-control as well as individualization and high intensification of training are provided.

3. Investigated in this work Tatar educational portals differ in both format and content. Each of them is demanded by the appropriate audience and provides the opportunity to obtain relevant information in the Tatar language in various aspects of Tatar culture, in the subjects of humanitarian and natural-scientific units. Separate portals are a platform for sharing best practices, embedding pedagogical findings, and stating one's point of view on topical issues of Tatar linguistics.

\section{Conclusion}

Modern information technology are becoming an integral part of the educational process, as the use of online resources contributes to the intensification and improvement of it's quality and effectiveness. As a modern educational model, they allow users to improve their language skills, discover new values, to broaden their linguistic horizons and develop communicative culture. Educational portals can be different in scope, objectives and contents, however, they are one of the most modern means of obtaining the necessary information and language learning, as they are most available and time-saving; diverse and colorful in terms of the flow of the material and ensure both its visual and auditory perception. They 
combine diverse types of information: videos, texts, graphics, animations, and sounds. In our opinion, active development of computer technologies will contribute to the emergence of the new education portals in Turkic languages in the near future.

\section{Acknowledgements}

Work is performed in accordance with the Program of the Government of the Russian Federation for increasing of competitiveness of Kazan Federal University.

\section{References}

1. Huseynov G. A., Fathullova K. S., Denmuhametova E. N., testing students' communicative competence in the course of studying of the Tatar language//Scientific journal of applied Sciences. - 2015. .10, it is.10. - S. 663-666

2. Rakhimov D. I., Yusupova Z. F. Language training of migrant workers: methodological recommendations for teachers//Language and literature. - 2016. .7, Is.3. - S. 314-317.

3. N. Rashat Yakupov, Kadryia Fathullova S., E. N. Denmukhametova The system of testing levels in the Tatar language proficcience// Journal of language and literature, 2016, Volume. 7. 1. PP. 223-228

4. Online course of the Kazakh language [Electronic pecypc]. Website Online course of the Kazakh language, URL: www.soyle.kz (date accessed: 18.05.2017).

5. Distance learning of the Uzbek language [Electronic pecypc]. URL: http://www.wscheck.net/www.onatili.uz?projectNam $\mathrm{e}=$ urladviser (date accessed: 18.05.2017).

6. Bashkir site [Electronic pecypc]. URL: http://f13.ucoz.net/ (accessed: 18.05.2017).

7. ANA EF the BODY [Electronic resource]. Onlineschool "ANA TELE", URL: http://anatele.ef.com (date accessed: 18.05.2017).

8. Fathollah K. S. E-learning technologies in teaching Tatar language // Tatarika, 2016. -№ 1(6). - Pages 189-194

9. Fathollah K. S., Kirillova Z. N., Yusupova A. S. Linguo-didactic peculiarities of Tatar language teaching / / LIVING, 2014, №11(8), pp. 507-511

10. Yuisufuva Z. And Yusupov.. Mugtasimova G. R., Denmukhametova E. N. Paroemiological and culturespecific units of the Tatar language // Journal of modern methods of teaching, 2016. Special issue (December).161-165

11. Galimova G. N., Yusupova A. S., Dinmuhamedova E. N., Mustakimov G. R. poslovicy Tatar language as a reflection of Western and Eastern cultures //Modern journal of language teaching methods. 2016, PP.198-201 